\title{
COMPARATIVE EFFECTIVENESS OF DEXAMETHASONE VERSUS KETOPROFEN PHONOPHORESIS IN MANAGEMENT OF CARPAL TUNNEL SYNDROME

\author{
Akram A. Ahmed ${ }^{1}$; Amal H.M. Ibrahim² ; Tamer M. Belal $^{3}$
} and Ghada Esmaeil ${ }^{4}$ \\ 1.Department of Physiotherapy, Talkha Central Hospital, Dakahlia, \\ 2.prof. of Physical Therapy for Basic Science,Faculty of Physical Therapy, Cairo University, Egypt. \\ 3.prof of Neurology, Faculty of Medicine, Mansoura University. Egypt. \\ 4.Assisst.prof. of Physical Therapy for Basic Science,Faculty of Physical Therapy, Cairo University, Egypt
}

Key Words: Carpal Tunnel Syndrome, Semmes Weinstein Monofilaments, Phonophoresis, and Nerve gliding.

\section{ABSTRACT}

Aim: to compare between the effect of dexamethasone phonophoresis with nerve gliding, ketoprofen phonophoresis with nerve gliding and nerve gliding in management of mild to moderate carpal tunnel syndrome (CTS).Subjects.Sixty patients suffering from mild to moderate carpal tunnel syndrome were selected from Department of Neurology, Mansoura University. Their age ranged between 20 and 30 years old. They were divided randomly into three equal groups. Group A (study group); 20 patients receive dexamethasone phonophoresis and nerve gliding, group B (study group); 20 patients receive ketoprofen phonophoresis and nerve gliding, and Group (C- control group); 20 patients receive nerve gliding. All groups were assessed before and after treatment using visual analogue scale (VAS) for pain, Semmes Weinstein Monofilaments (SWM) for skin sensation, and handheld dynamometer (HHD) for hand grip strength.The treatment program was given 3 times/ week for 6 weeks for the three groups. Results: There were significant decrease in VAS after-treatment, mean difference for VAS after-treatment show significance between group A versus group $\mathrm{C}(\mathrm{P}=0.0001 ; \mathrm{P}<0.05)$ and group $\mathrm{B}$ versus group $\mathrm{C}$ $(\mathrm{P}=0.0001 ; \mathrm{P}<0.05)$, but no significant difference between group $\mathrm{A}$ versus group $\mathrm{B}(\mathrm{P}=1.000 ; \mathrm{P}>0.05)$. Mean differences between groups showed that the dexamethasone phonophoresis plus nerve gliding group (Group A) give the highest VAS value. The repeated measure ANOVA revealed that a significant difference among HHD in group A $(\mathrm{P}=0.0001$; $\mathrm{P}<0.05$ ), but no significant differences within group $\mathrm{B}$ and group $\mathrm{C}$ 
$(\mathrm{P}=0.118 ; \mathrm{P}>0.05)$. Mean differences among groups show siginificant improvent in SWM. Conclusion: it could be concluded that dexamethasone phonophoresis and ketoprofen phonophoresis combined with nerve gliding are effective in the treatment of carpal tunnel syndrome than nerve glid alone.

\section{INTRODUCTION}

Carpal tunnel syndrome (CTS) is a common medical entrapment neuropathy of the upper extremity, which causes pain and paresthesia's in the distribution of the median nerve, numbness, and tingling in the hand and arm occurs when the median nerve is squeezed or compressed as it travels through the wrist (Wipperman, \& Goerl. 2016). These sensations may be felt in the thumb, index finger, middle finger, and the radial side of the ring finger (Burton et al., 2014).

Obesity, forceful use of the hand, position of the hand, vibration, monotonous wrist activity, pregnancy, genetic heredity, and rheumatoid inflammation are risk factors for CTS. (Yeh et al., (2020) Rhode \& Rhode, (2016)

It is important to diagnose and treat CTS, because delay may result in irreversible median nerve damage with persistent symptoms and permanent disability (Keith et al., 2009). Various possibilities or treatment including surgical and conservative treatments have been used for CTS (Karatay et al., 2009). Conservative treatment of CTS would seem to be preferable as the initial treatment choice, particularly for mild to moderate cases (Gerritsen et al., 2002). Conservative treatments include rest and avoidance of extreme activity with the hand, ultrasound and laser therapy, splinting the wrist in a neutral position, non steroidal anti-inflammatory drugs, oral steroids, local corticosteroid injections, and surgery to decompress the median nerve segment.Iontophoresis and phonophoresis methods were also used to introduce locally antiinflammatory steroid drugs for CTS treatment (Karatay et al., 2009).

However, there are some controversies about the reported results by these studies. Banta (1994), suggested that iontophoresis may become an alternative to steroid injections to the carpal tunnel region. Later, Dakowicz and Latosiewicz. 2005, showed that using a combination of hydrocortisone iontophoresis and ultrasound therapy may diminish the symptoms of patients with mild to moderate CTS. Gokoglu et al., 2005, also reported a successful treatment by iontophoresis of dexamethasone sodium phosphate (Dex-P) in patients with CTS. In other study, (Amirjani et al., 2009) were reported superiority between iontophoresis and phonophoresis methods to deliver betamethasone or corticosteroid drugs for CTS treatment 


\section{MATERIALS AND METHODS}

trial.

The study was designed as a prospective, randomized controlled

\section{Participants}

Sixty patients were selected from departments of neurology, Mansoura University Hospitals by neurology physician.Patient's age ranged from 20 to 30 years with mild to moderate CTS diagnosed by clinical examination, electrophysiological study, and ultrasound.

Patients will be divided randomly into three equal groups;

Group (A); 20 patients receive dexamethasone phonophoresis and nerve gliding.

Group (B); 20 patients receive ketoprofen phonophoresis and nerve gliding.

Group (C); 20 patients receive nerve gliding.

All groups were assessed before and after 6 weeks of treatment using visual analogue scale (VAS) for pain, Semmes Weinstein Monofilaments (SWM) for skin sensation, and handheld dynamometer (HHD) for hand grip strength.

\section{Intervention:}

Participants in group (A), received phonophoresis of local dexamethasone gel on the palm of their wrist crease using ultrasound continuous mode, $1.5 \mathrm{~W} / \mathrm{cm} 2$ intensity, and $1 \mathrm{MHz}$ frequency for 5 minutes with nerve gliding. Participants in group (B) received phonophoresis of local ketoprofen gel on the palm of their wrist crease using ultrasound continuous mode, $1.5 \mathrm{~W} / \mathrm{cm} 2$ intensity, and $1 \mathrm{MHz}$ frequency for 5 minutes with nerve gliding.Participants in group (C) control group, received nerve gliding only.

\section{Statistical Analysis:}

Shapiro-Wilk test was used, to examine normalitydistribution of all data $(\mathrm{P}>0.05)$ after removal outliers that detected by box and whiskers plots. Additionally, Levene's test for testing the homogeneity of variance revealed that there was no significant difference $(\mathrm{P}>0.05)$. The data is normally distributed and parametric analysis is done. The statistical analysis was conducted by using statistical SPSS Package program version 25 for Windows (SPSS, Inc., Chicago, IL). Quantitative descriptive statistics data including the mean and standard deviation for VAS, score variables.Qualitative descriptive statistics data including the number and percentage for filaments variables. Chi-square test used to compare between before- and after-treatment of filaments within each group. Also, to compare among groups $\mathrm{A}, \mathrm{B}$, and $\mathrm{C}$ at before-treatment and after-treatment. 


\section{RESULTS AND DISCUSSION}

The results revealed that there were significant differences in VAS after-treatment between group $\mathrm{A}$ and group $\mathrm{C}(\mathrm{P}=0.0001 ; \mathrm{P}<0.05)$ and group $\mathrm{B}$ versus group $\mathrm{C}(\mathrm{P}=0.0001 ; \mathrm{P}<0.05)$, but no significant difference between group $\mathrm{A}$ versus group $\mathrm{B}(\mathrm{P}=1.000 ; \mathrm{P}>0.05)$, Mean differences between groups showed that the dexamethasone phonophoresis plus nerve gliding group (Group A) give the highest VAS value (Table 1). In HHD, the statistical analysis by repeated measure ANOVA revealed that a significant difference group A $(\mathrm{P}=0.0001 ; \mathrm{P}<0.05)$, but no significant differences within group $\mathrm{B}(\mathrm{P}=0.174 ; \mathrm{P}>0.05)$ and group $\mathrm{C}(\mathrm{P}=0.118$; $\mathrm{P}>0.05)$. Mean differences between groups showed that the dexamethasone phonophoresis plus nerve gliding group (Group A) give the highest HHD value (Figure 1). In Semmes Weinstein monofilaments among groups A, B, and $\mathrm{C}$. The statistical analysis byChi-square test revealed that there was a significant difference $(\mathrm{P}=0.0001 ; \mathrm{P}<0.05)$ in filaments at after treatment among groups $\mathrm{A}, \mathrm{B}$, and $\mathrm{C}$ (Table 2).

Table (1): Mean values before- and after-treatment VAS within each group.

\begin{tabular}{|c|c|c|c|}
\hline \multicolumn{4}{|c|}{ VAS (Mean \pm SD) } \\
\hline Items & Group A & Group B & Group C \\
\hline Before treatment & $6.76 \pm 1.11$ & $6.31 \pm 0.76$ & $7.50 \pm 0.88$ \\
\hline After treatment & $0.00 \pm 0.00$ & $0.00 \pm 0.00$ & $3.90 \pm 1.02$ \\
\hline \multicolumn{4}{|c|}{ Mixed MANOVA (Overall effect) } \\
\hline MANOVA-test & F-value & P-value & Significance \\
\hline Group effect & 130.366 & $0.0001 *$ & $\mathbf{S}$ \\
\hline Time effect & 152.806 & $0.0001 *$ & $\mathbf{S}$ \\
\hline Interaction effect & 48.258 & 0.0001* & $\mathbf{S}$ \\
\hline
\end{tabular}

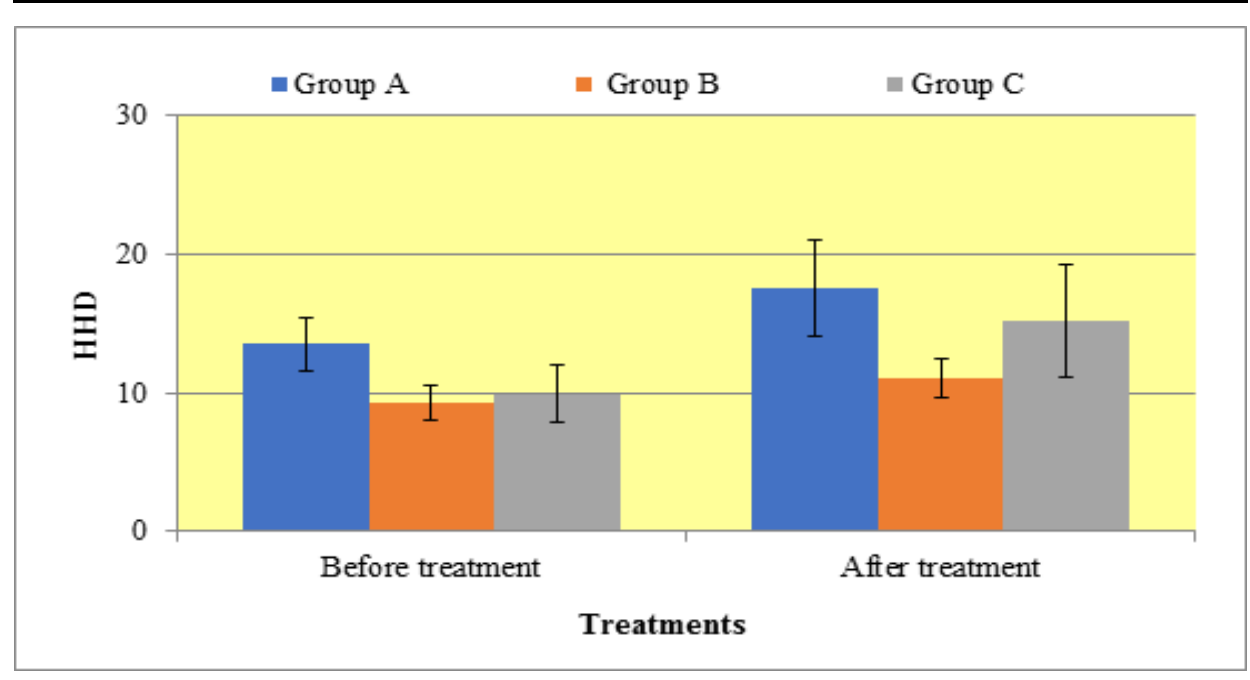

Figure (1): Mean values of HHD at before- and after-treatment among groups. 
Egypt. J. of Appl. Sci., 36 (7-8) 2021

Table (2): Distribution and comparative of filaments among groups

\begin{tabular}{|c|c|c|c|c|c|c|c|}
\hline \multirow{3}{*}{\multicolumn{2}{|c|}{ Items }} & \multirow{2}{*}{\multicolumn{3}{|c|}{$\begin{array}{c}\text { Filaments } \\
\text { Groups }\end{array}$}} & \multirow{3}{*}{$\begin{array}{l}\chi^{2-} \\
\text { value }\end{array}$} & \multirow{3}{*}{ P-value } & \multirow{3}{*}{$\begin{array}{l}\text { Significanc } \\
\text { e }\end{array}$} \\
\hline & & & & & & & \\
\hline & & Group A & Group B & Group C & & & \\
\hline \multirow{3}{*}{ 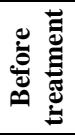 } & $\begin{array}{l}\text { Diminished } \\
\text { sensation }\end{array}$ & $10(50 \%)$ & $\begin{array}{c}20 \\
(100 \%)\end{array}$ & $13(65 \%)$ & \multirow{3}{*}{37.674} & \multirow{3}{*}{ 0.0001* } & \multirow{3}{*}{$\mathbf{S}$} \\
\hline & Normal sensation & $10(50 \%)$ & 0 (0\%) & $0(\mathbf{0 \%})$ & & & \\
\hline & No sensation & 0 (0\%) & $0(0 \%)$ & $7(35 \%)$ & & & \\
\hline \multirow{4}{*}{ 离 } & Total recover & $10(50 \%)$ & $\begin{array}{c}20 \\
(100 \%)\end{array}$ & $\mathbf{0}(\mathbf{0 \%})$ & \multirow{4}{*}{80.000} & \multirow{4}{*}{$0.0001 *$} & \multirow{4}{*}{$\mathbf{S}$} \\
\hline & No recover & 0 (0\%) & $\mathbf{0}(\mathbf{0 \%})$ & $8(40 \%)$ & & & \\
\hline & Normal sensation & $10(50 \%)$ & $\mathbf{0}(\mathbf{0 \%})$ & 0 (0\%) & & & \\
\hline & Mild recover & $0(0 \%)$ & $\mathbf{0}(0 \%)$ & $12(60 \%)$ & & & \\
\hline
\end{tabular}

Group A: receives dexamethasone phonophoresis plus nerve gliding

Group B: receives ketoprofen phonophoresis plus nerve gliding

Group C: receives nerve gliding only (control group)

Data are expressed as number and percentage

square value P-value: probability value

$\chi^{2}$-square value: Chi-

* Significant $(\mathbf{P}<0.05) \quad$ NS: non-significant

S: significant

Hoshang et al., 2011, designed a study to compare the effect of iontophoresis and phonophoresis of dexamethasone (DXA) on 51hands with mild or moderate CTS. They concluded that using phonophoresis of DXA is more effective for CTS treatment than iontophoresis.

Hong et al., 1988, has been usedUS therapy as a treatment for various conditions including CTS. It converts electrical energy into a sound wave. The wave transmits through the skin into the deeper tissue and increases tissue temperature. The biophysical effects of US on CTS include (1) stimulation of nerve regeneration; (2) increasing the conductivity of nerve; and (3) reducing the inflammatory process.

Phonophoresis is a modified method that uses US to enhance cutaneous absorption of topical anti-inflammatory drugs from the skin into the deeper target tissues. It is a noninvasive and low- risk technique. It combines the treatment of US and anti-inflammatory drugs; therefore, increased beneficial effects are expected. There are many reports about its effects on musculoskeletal conditions. Recently, the reports of phonophoresis treatment in CTS patients have shown positive results using a variety of drugs and study designs.

Yildiz et al., 2011, conducted a study ona randomized, doubleblind, controlled trial compared the efficacy of US and ketoprofen $\mathrm{PH}$ in mild to moderate CTS. The results showed that the ketoprofen PH group had a significantly decreased Visual Analogue Scale (VAS) of pain compared to the US group. Another study by Soyupek et al., 2012, conducted a single-blind study to compare the efficacy of conservative treatments between four groups of CTS patients: (1) PH of corticosteroid (PH-CS); (2) PH of NSAIDs (PH-NSAIDs-diclofenac gel); (3) local corticosteroid injection (LCSI); and (4) volar wrist splint. The results 
showed that PH-CS group was markedly improved in electrophysiological studies, grip strength, and functional status. There were significant improvements in grip strength, pegboard test, and pain intensity in the PH- NSAIDs group. However, the patients who received US were not included in this study. The superiority of PH over US treatment was inconclusive.

Bakhtiary et al., 2013, conducted a randomized clinical study compared the effects of $\mathrm{PH}$ with iontophoresis technique in CTS patients. Both treatments used the same dose of $0.4 \%$ dexamethasone sodium phosphate. The results revealed that the $\mathrm{PH}$ method was more effective than iontophoresis in improving hand functions and electrophysiological parameters.

Although many studies have reported the benefits of PH treatment in CTS, the determination of whether PH is better than standard US is still inconclusive as well as whether NSAIDs or dexamethasone sodium phosphate is better for $\mathrm{PH}$.

Jariya Boonhong 2019 has conducted a study on effectiveness of phonophoresis treatment in carpal tunnel syndrome that comparing between three randomized groups .All three groups received 10 sessions of $1-\mathrm{MHz}$ frequency, $1.0 \mathrm{w} / \mathrm{cm} 2$ intensity ultrasound wave with stroking technique, continuous mode, at the palm side of the hand over the carpal tunnel area-10 minutes per session, two to three times per week for 4 weeks, for a total of 10 sessions. During each session, the patients received $15 \mathrm{~cm} 3$ of study gel according to the study groups. The PH-P group received $0.5 \%$ piroxicam gel mixture (equivalence of $20 \mathrm{mg}$ of piroxicam). The PH-Dex group received $0.4 \%$ dexamethasone sodium phosphate gel mixture (equivalence $60 \mathrm{mg}$ of dexamethasone). The US group received nondrug gel. This study revealed that US, PH-P, and PH-Dex (using $1 \mathrm{MHz}$ frequency and $1.0 \mathrm{w} / \mathrm{cm} 2$ intensity) were not effective in improving electrodiagnostic parameters (DSL and DML) in mild to moderate CTS but did improve clinical symptoms and functional status without the between-group statistical differences. $\mathrm{PH}$ is not superior to standard US in management of CTS.

\section{CONCLUSION}

The results obtained from the current study showed that: Both dexamethasone and ketoprofen phonophoresis combined with nerve gliding were more effective in treatment of mild to moderate carpal tunnel syndrome than nerve gliding alone.

Source of Funding: This study received no financial support.

Conflict of Interest: The authors have no conflict of interest to declare.

\section{ACKNOWLEDGMENTS} the study

The authors would like to thank all patients who participated in 


\section{REFERENCES}

Amirjani, N. ; N.L. Ashworth ; M.J. Watt and et al.(2009): Corticosteroid iontophoresis to treat carpal tunnel syndrome: a double-blind randomized controlled trial. Muscle Nerve.; 39:627-633.

Atroshi, I. ; C. Gummesson ; R. Johnsson and et al.(1999): Prevalence of carpal tunnel syndrome in a general population. JAMA.; 282:153-158.

Blumenthal, S. ; S. Herskovitz ; J. Verghese and et al.(2006): Carpal tunnel syndrome in older adults. ;34:78-83.

Burton, C. ; L.S. Chesterton ; G. Davenport and et al. (2014): Diagnosing and managing carpal tunnel syndrome in primary care.;64:262-263.

Carpal tunnel syndrome. BMJ. (2014):; 349:g6437 doi: https://doi.org/10.1136/bmj.g6437.

Chammas, M. ; J. Boretto ; L.M. Burmann and et al.(2014): Carpal tunnel syndrome - part I (anatomy, physiology, etiology and diagnosis). ; 49:429-436.

Gerritsen, A.A. ; M.C. de Krom ; M.A. Struijs ; R.J. Scholten ; H.C. and LM. de Vet Bouter (2002): Conservative treatment options for carpal tunnel syndrome: a systematic review of randomized controlled trials. J Neurol. ;249(3):272-80.

Gurcay, E. ; E. Unlu ; A.G. Gurcay and et al.(2012): Assessment of phonophoresis and iontophoresis in the treatment of carpal tunnel syndrome: a randomized controlled trial. Rheumatol Int. ; 32:717-722.

Karatay, S. ; R. Aygul ; M.A. Melikoglu and et al.(2009): The comparison of phonophoresis, iontophoresis and local steroid injection in carpal tunnel syndrome treatment. Joint Bone Spine.; 76: 719-721.

Keith, M.W. ; V. Masear ; P.C. Amadio and et al.(2009): Treatment of carpal tunnel syndrome. J Am Acad Orthop Surg.; 17:397-405.

Rhode, B.A. and W.S. Rhode (2016) Occupational Risk Factors for Carpal Tunnel Syndrome. MOJ Orthopaedic\&Rheumatolgy, 4(2): 00131. DOI: 10.15406/mojor.2016.04.00131.

Gökoğlu, Figen M.D. ; M.D. Fndkoğlu Gülin ; Z. Yorgancoğlu and et al.,(2005): American Journal of Physical Medicine \& Rehabilitation: 84(2):2-96.

Shi, Q. and J.C. Macdermid (2011): Is surgical intervention more effective than non-surgical treatment for carpal tunnel syndrome? A systematic review. J Orthop Surg Res 2011;6:17.

Wipperman, J. and K. Goerl (2016). Carpal Tunnel Syndrome: Diagnosis and Management. American Family Physician, 94(12): 993-999. 
Yeh, K.T. ; R.P. Lee ; T.C. Yu and et al. (2020). Risk factors for carpal tunnel syndrome or trigger finger following distal radius fracture: a nationwide study. Scientific Reports 10: 469. https://doi.org/10.1038/s41598-020-57415-x.

\section{الفعالية المقارنة للايكساميثازون مقابل الكيتويروفين في}

\section{علاج متلازمة النفق الرسفي}

أكرم عبدالمنعم أحمد 1 ، أمل حسن محمد إبراهيم² ، تامر محمد بلال3 ، غ غادة إسماعيل

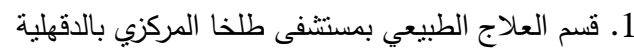

2. أستاذ، قسم العلاج الطبيعي للعلوم الأساسية ، كلية العلاج الطبيعي ، جامعة القاهرة ، مصر.

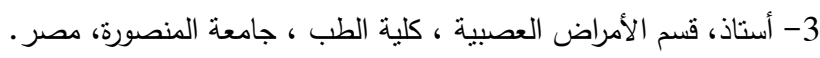

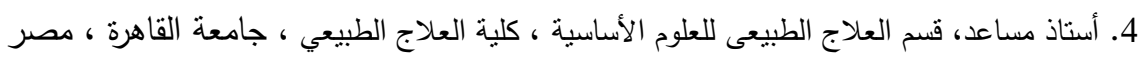

الهذف: المقارنة بين تأثيرادخال الديكساميثازون عن طريق الموجات فوق الصوتية مع تمارين انزلاق

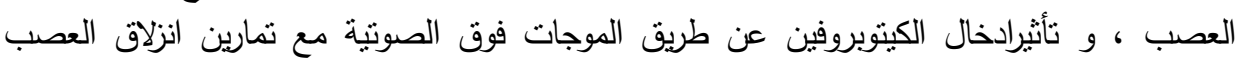
وتمارين انزلاق العصاب في علاج متلازمة النفق الرسغي الخفيفة إلى المتوسطة. المشاركين: 60

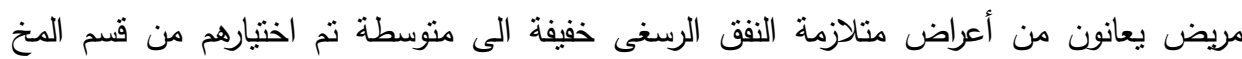

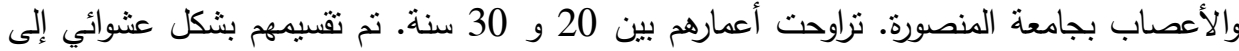

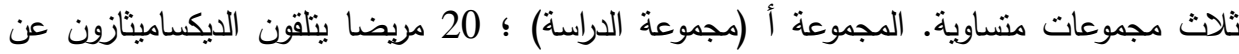

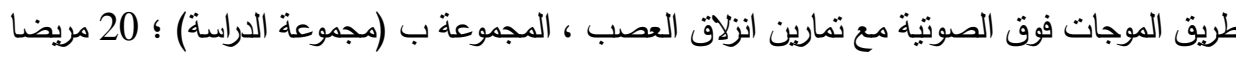

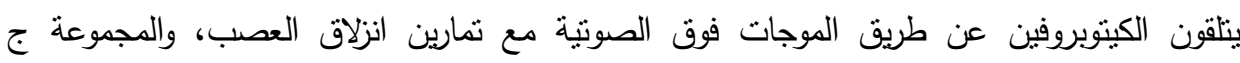

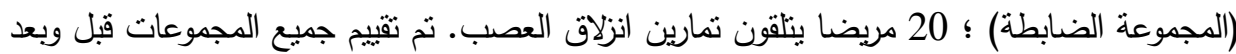

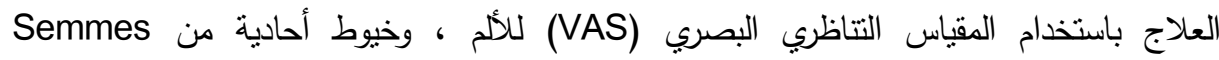
، لقإختبار الاحساس ، ومقياس الدينامومتر المحمول (HHDeinstein (SWM)

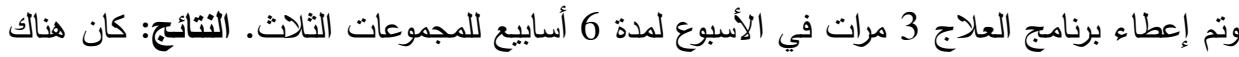

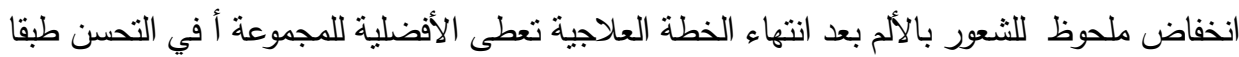

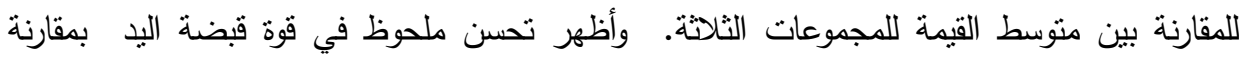

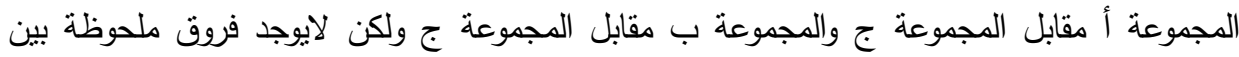

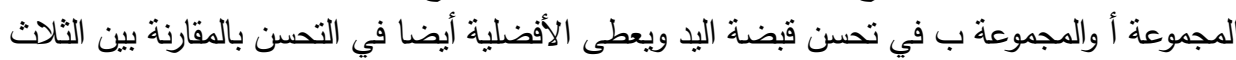

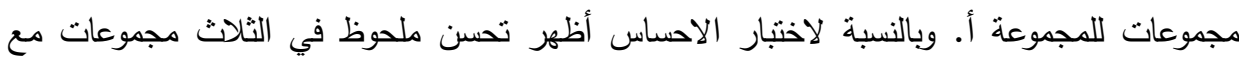

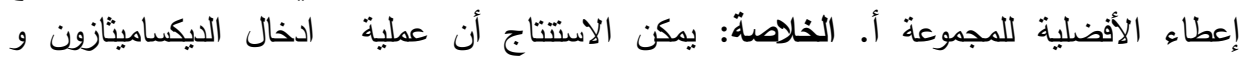

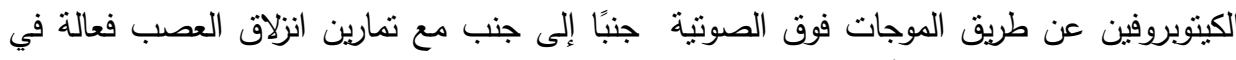

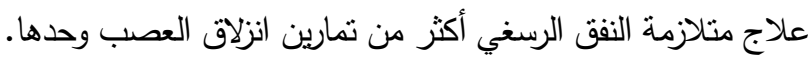
الكلمات المفتاحية: متلازمة النفق الرسغي ، الثارئ الثعيرات الأحادية سيميس وينشتاين ، الرحلان

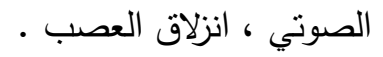

